doi:10.1038/nclimate2474

http://www.nature.com/nclimate/journal/v5/n2/full/nclimate2474.html

\title{
Barrier island bistability induced by biophysical interactions
}

Orencio Durán Vinent ${ }^{1,2}$ and Laura J. Moore ${ }^{1}$

${ }^{1}$ University of North Carolina, Department of Geological Sciences, 104 South Rd, Mitchell Hall, Campus Box 3315 , Chapel Hill, NC 27515 USA

${ }^{2}$ Now at: MARUM-Center for Marine Environmental Sciences, University of Bremen, Leobener Str., D-28359 Bremen, Germany

Barrier islands represent about $\mathbf{1 0 \%}$ of the world's coastline ${ }^{1}$, sustain rich ecosystems, host valuable infrastructure and protect mainland coasts from storms. Future climate-change-induced increases in the intensity and frequency of major hurricanes ${ }^{2}$ and accelerations in sea level rise ${ }^{3,4}$ will have a significant impact on barrier islands ${ }^{5,6}$ — leading to increased coastal hazards and flooding — yet our understanding of island response to external drivers remains limited ${ }^{1,7-8}$. Here, we find that island response is intrinsically bistable and controlled by previously unrecognized dynamics: the competing, and quantifiable, effects of storm erosion, sea level rise, and the aeolian and biological processes that enable and drive dune recovery. When the biophysical processes driving dune recovery dominate, islands tend to be high in elevation and vulnerability to storms is minimized. Alternatively, when the effects of storm erosion dominate, islands may become trapped in a perpetual state of low elevation and maximum vulnerability to storms, even under mild storm conditions. When sea level rise dominates, islands become unstable and face possible disintegration. This quantification of barrier island dynamics is supported by data from the Virginia Barrier Islands, U.S. and provides a broader context for considering island response to climate change and the likelihood of potentially abrupt transitions in island state.

Barrier islands respond to rising sea level by migrating landward or drowning ${ }^{7,9-10}$. Landward migration is driven mostly by storms and is controlled by island elevation. Extensive measurements of dune elevation performed at the Virginia Barrier Islands ${ }^{11}$, a relatively undisturbed barrier system including 12 islands, show a bimodal distribution of barrier island elevation with two well-defined island types: low-elevation and highelevation islands (Fig. 1, Supplementary Fig. 1). Low islands lacking vegetated dunes are relatively narrow and prone to frequent overwash, resulting in rapid landward migration (Fig. 1a,b,g) and low biodiversity (as in the case of the islands associated with the Mississippi Delta, e.g., The Chandeleur Islands). In contrast, high islands with well-developed dunes resist storm impacts, are wider and migrate slowly (if at all, Fig. 1c,d,g) and support a rich ecosystem and/or human development. In this way, barrier island evolution is fundamentally linked to dune dynamics. However, because vegetated dunes both protect islands from storm impacts and are themselves 
eroded by storms and affected by rising sea level, island dynamics ultimately arise from the competition between dune erosion and dune formation.

We investigate this competition by adding the effects of storms and sea level rise into a model of the physical and biological processes involved in coastal dune formation ${ }^{14}$, and then simulating long-term barrier island dynamics as multiple cycles of dune formation alternating with dune erosion during high water events (HWE; including all events - arising from local and distant storms - in which total water level R, i.e. mean sea level + tides + storm surge + wave runup, is above the mean high water level (MHWL)). The resulting model consists of a set of differential equations describing the morphodynamic feedback between aeolian sand transport and topography, the interaction between vegetation growth and sand transport, and the effects of the shoreline on sand transport, as well as the newly added effects of vegetation sensitivity to salt water inundation ${ }^{15,16}$, storminduced sand transport above MHWL, and RSLR (Methods and Supplementary Methods). For simplicity all boundary and initial conditions are uniform in the alongshore direction (i.e. the island has alongshore symmetry) and thus, island elevation is equivalent to local dune elevation.

Simulations show that immediately following an overwash event, island elevation is too low to sustain the growth of 'dune-building' plants (Fig. 2a). In the absence of vegetation, small non-vegetated dunes slowly nucleate at the back of the beach in response to the interaction between morphology and wind flow (Fig. 2c, Supplementary Fig. 2) following the same mechanisms as the nucleation of desert dunes ${ }^{17}$. Once sand elevation is sufficiently high to allow vegetation recovery (a threshold defined by the minimum elevation $Z_{c}$ above the MHWL that 'dune-building' plants can effectively grow, see Methods) vegetated dune growth begins as plants trap sand, thereby accelerating vertical accretion and leading to rapid dune building. In the absence of storm erosion, dunes eventually reach a maximum $\operatorname{size}^{14}$ (Fig. 2a,b).

Consideration of the processes behind vegetation recovery, and thus dune recovery, shows that the vegetation recovery time $T_{v}$ increases with relative sea level rise because the rate of net surface accretion-which prevents frequent salt-water inundation of the backshore and leads to vegetation recovery-is the difference between the growth rate $\mathrm{G}_{0}$ of the non-vegetated incipient dunes and the rate $\mathrm{S}$ of RSLR. The growth rate $\mathrm{G}_{0}$ scales as the ratio of the mean aeolian sand flux at the beach $\mathrm{q}_{0}$, an increasing function of wind intensity and (dry-) sand supply, and the non-vegetated dune wavelength $\lambda^{17}$. The vegetation recovery time $T_{v}$ then relates the primary 
factors influencing vegetation and dune recovery: vegetation sensitivity to inundation $\left(\mathrm{Z}_{\mathrm{c}}\right)$, aeolian transport (q0), and RSLR (S): $T_{v} \approx Z_{c} /\left(\beta q_{0} \lambda^{-1}-S\right)$, with fitting parameter $\beta \approx 0.1$ (Supplementary Fig. 3).

After imposing periodic high water events (HWEs) with random total water level R, the stochastic dynamics of barrier island elevation is controlled by the ratio of the vegetation recovery time $\left(\mathrm{T}_{\mathrm{V}}\right)$ and the period $\left(\mathrm{T}_{\mathrm{HWE}}\right)$ of HWEs (Fig. 3a-c). This ratio characterizes the competition between external erosive and internal recovery processes and therefore we call it the 'vulnerability' index $\left(\gamma=\mathrm{T}_{\mathrm{v}} / \mathrm{T}_{\mathrm{HWE}}\right)$. When the period of HWEs is larger than the vegetation recovery time $(\gamma<1)$, vegetation recovers before the next HWE, thus enabling rapid dune growth (Fig. 3a). Since dune erosion is mainly controlled by the ratio between $\mathrm{R}$ and dune elevation $\mathrm{H}^{18}$ (Supplementary Fig. 4), rapid dune recovery leads to a negative feedback in which higher elevation, and therefore lower vulnerability to wave erosion, allows dunes to remain close to their maximum height. This highelevation state thus represents a stable dynamical equilibrium for barrier island elevation. When the period of HWEs is shorter than the vegetation recovery time $(\gamma>1)$, low areas devoid of vegetation cannot recover before the next HWE. They remain vulnerable to erosion and are thus kept in a low-elevation state. In contrast, well-developed dunes are less prone to overwash and even when partially eroded - as long as some elevation and vegetation remain - they can recover quickly, evolving toward the high-elevation state. Therefore, for $\gamma>1$ there is a tendency for a barrier island to exist either as a stable high island or a stable low island and the island becomes bistable (Fig. 3b,c). The onset of the bistable behavior at $\gamma=1$ has been verified numerically for varying winds, rates of RSLR and vegetation sensitivities (Fig. 3d,e).

The predicted bistability of island dynamics offers an explanation for the bimodal probability distribution function of island elevation observed for the Virginia Barrier Islands, along the mid-Atlantic coast of the U.S.. Assuming the temporal randomness of HWEs impacting a given location of the island is equivalent to the spatial randomness of HWEs acting at different locations alongshore, it is possible to compare qualitatively the simulated time series of local island elevation (e.g. Fig. 2b) to the measured alongshore elevation (Fig. 1e). In addition to predicting the observed bimodal distribution of dune elevation (Fig. 1f), the model also reproduces increases in shoreline change rate (used as a proxy for island migration rate) with decreasing average island elevation (Fig. 1g, h), which can be understood as an increasing contribution to average island migration rates from the rapidly migrating low sections of the island. 
Within the bistable regime the stochastic nature of high water events (HWE), allows barrier islands to explore alternate equilibrium states with a certain probability. Transition from a high to a low state can be triggered either by low-frequency high-energy events such as large storms, or by frequent medium-energy events (Fig. 3a-c, Supplementary Fig. 5). Because the conditions to sustain a mature vegetated dune are very different than those needed to build it in the first place, there is a hysteresis in the response of island elevation to changing conditions, with dune recovery taking place at a lower vulnerability index than the one required for severe dune erosion (Supplementary Fig. 5a). Therefore, the fact that an island is in a high state is not enough to conclude that it can recover quickly once in the low state, as can be seen in Fig. 3b-c where dune recovery takes longer for increasing vulnerability indices. Indeed, simulations show that the probability of dune, and therefore island, recovery (i.e. of entering the attractive basin of the high state) decreases exponentially with the vulnerability index (Fig. 3e), which means that the island will remain low in elevation for exponentially longer times.

The vulnerability index, which can be rewritten using the scaling of the vegetation recovery time as

$$
\gamma=Z_{c} T_{H W E}^{-1} /\left(\beta q_{0} \lambda^{-1}-S\right),
$$

summarizes the role of the key factors driving barrier island response (Fig. 4). The transition from a stable high island to a bistable one is accelerated by higher rates of RSLR, more vulnerable vegetation or more frequent HWE, but retarded by increasing aeolian transport. For negative net accretion rates $(\gamma<0)$ the island enters a new unstable regime in which the low-elevation state becomes intertidal/subtidal (i.e., below the MHWL) and the island may disintegrate (Fig. 4). Therefore, the vulnerability index provides a deeper insight into long-term island dynamics, regardless of perturbations that may occur in the short term. For example, the progressive disintegration of barrier islands along the Mississippi delta (e.g. the Chandeleur Islands) that has been attributed to a series of recent major storms ${ }^{20}$, could alternatively be understood as a consequence of transition into the unstable regime (Fig. 4) triggered by an increase in RSLR compounded by a reduction in sand supply 9 Similarly, the Virginia Barrier Islands appear to have experienced transition to the bistable regime, in which high and low islands co-exist, possibly driven by locally high $\operatorname{RSLR}^{4}$ and a reduction in aeolian sand transport arising from the combined effects of shell armoring ${ }^{21}$ and exposure of marsh platform (i.e. less sand supply) on the foreshore (Fig. 1i, j).

The bistable dynamics suggested by model results contributes to a growing literature reporting the existence of alternate stable states in ecosystems as diverse as arid lands, forests, lakes, oceans and coral reefs ${ }^{22}$ and more recently, shallow coastal bays ${ }^{23}$. Along with a few more recent studies ${ }^{24,25}$, we demonstrate the importance of 
biophysical feedbacks in leading to state changes that affect not only the ecosystem that inhabits the landscape, but the morphology of the landscape itself. As in all multi-state systems, barrier islands — which are often heavily developed, and which serve as important interfaces between the marine and terrestrial realms - may cross the threshold to bistability silently, without providing observable evidence until the state change becomes locked in place by a random event. Additionally, because barrier islands are coupled to adjacent coastal ecosystems such as shallow coastal bays and marshes ${ }^{26}$, which also exhibit multiple stable states ${ }^{23}$, a disturbance that triggers a transition in island state may initiate a cascade of transitions across the broader landscape. For landscapes and ecosystems generally, analytical expressions for boundaries between system regimes (e.g., here, from stable to bistable, or from bistable to unstable), have the potential to be even more useful than leading indicators ${ }^{27}$ that merely warn of an impending change. For example, control parameters such as the vulnerability index have the potential to provide a means for assessing the likelihood that a landscape system will transition to a new regime under a given set of conditions, as well as quantitative guidance on management strategies intended to decrease system vulnerability and increase resilience.

\section{Methods}

The coastal dune model describes the temporal evolution of the sand surface elevation $\mathrm{h}(\mathrm{x}, \mathrm{y}, \mathrm{t})$-defined relative to the mean high water level (MHWL) - and the cover fraction $\rho_{\mathrm{veg}}(\mathrm{x}, \mathrm{y}, \mathrm{t})$ for a single generic grass species. $\mathrm{x}$ is the cross-shore distance to the shoreline $(\mathrm{x}=0)$, which separates the foreshore $(\mathrm{x}<0)$ from the backshore $(\mathrm{x}$ $>0$ ), and $y$ is the alongshore coordinate. A complete description of the coastal dune model is provided in the Supplementary Methods and includes further details on the calculation of the aeolian transport and vegetation dynamics as well as the initial and boundary conditions used to integrate the model.

Aeolian sand transport: In the absence of storms, the sand flux $\vec{q}_{a}(x, y, t)$ is calculated from the bed wind shear stress, which depends on the surrounding topography and the vegetation cover, and the local sand transport threshold, which we assume is primarily controlled by the sand moisture content. For simplicity in the formulation, sand transport is described by volume, not mass, flux.

Storms: Storms are defined in the model as high water events (HWEs) with total water elevation R above the MHWL ( $\mathrm{R}$ is defined relative to the MHWL). HWEs are considered periodic with period $\mathrm{T}_{\mathrm{HWE}}$ and have 
constant duration.. $\mathrm{R}$ is randomly distributed following an Erlang distribution $R^{2} \bar{R}^{-3} e^{-3 R / \bar{R}}(\bar{R}$ is mean total water elevation) which has an exponential tail, in agreement with Ref. 28, and filters tidal events (i.e. there are no events for $R \rightarrow 0$ ).

Storm-induced sand transport: We derive a phenomenological expression to calculate the cross-shore sand flux $q_{s t}(x, y, t)$ for elevations between MHWL and R during high water events (HWE). Based on Ref. 29 (see Ref. 30 for the validation of a similar formulation), we assume the net sand flux $q_{s t}$ over many swash cycles is proportional to the cube of the average speed $U$ of the uprushing wave front, times the time $\delta t$ this particular location is submerged: $q_{s t} \propto U^{3} \delta t /(g T)$, with gravity g and timescale T. The net sand flux is weighted by a downslope contribution $\left(1-\partial_{x} h / \tan (\alpha)\right)$ that represents the tendency of the surface to reach the equilibrium foreshore slope $\tan (\alpha)$. From energy conservation, the kinetic energy of the uprushing wave front is approximately balanced by its potential energy. In this case $U \propto \sqrt{g(R-h)}$ and $\delta t \propto \sqrt{g(R-h)}$ (Ref. 29), which leads to

$$
q_{s t}=T^{-1}(R-h)^{2}\left(1-\partial_{x} h / \tan (\alpha)\right) .
$$

We choose the rescaled duration of HWEs to qualitatively reproduce the main erosional regimes described in Ref. 18 (Supplementary Fig. 4). Crucially, the predicted bistable behavior of barrier islands only depends on the existence of these erosional regimes and not on the details of the sand flux formulation.

Surface dynamics: Foreshore $(x<0)$ : We assume the foreshore to be always at equilibrium, defined by a constant slope of angle $\alpha$. This assumption implies aeolian erosion is balanced by accretion in the swash zone. As a result, the simulated foreshore acts as a sand reservoir supplying an unlimited amount of sediment to the backshore, effectively feeding dune formation and post-storm recovery. Shoreline $(x=0)$ : We assume, as a first approximation, that under RSLR the shoreline follows Bruun's rule and migrates landward at a rate $\dot{x}_{\text {shore }}$ proportional to the rate S of RSLR. Backshore $(x>0)$ : We calculate the change in the sand surface elevation $\mathrm{h}$ at the backshore from mass conservation as

$$
\partial h / \partial t=-\partial q_{s t} / \partial x
$$

during HWEs, and

$$
\partial h / \partial t=-\nabla \cdot \vec{q}_{a}-S+\dot{x}_{\text {shore }} \partial h / \partial x
$$

otherwise. The last two terms at the right hand side describe the effects of RSLR and appear because we define the surface elevation relative to the sea level and the shoreline position. 
Vegetation dynamics: As a first approximation, we assume a single generic grass species with a cover fraction $\rho_{\text {veg }}$ that is sensitive to sand erosion and accretion and that can increase up to the maximum cover $\rho_{\text {veg }}=1$ during a characteristic time $t_{v e g}$. We further assume plant growth is also sensitive to frequent salt-water inundation and thus to the proximity of the shoreline and to the elevation above MHWL, such that plants can effectively grow only landward of the vegetation limit $\mathrm{L}_{\mathrm{veg}}$ and in places higher than a minimum elevation $\mathrm{Z}_{\mathrm{c}}$. Thus,

$$
d \rho_{v e g} / d t=\left(1-\rho_{v e g}\right) t_{v e g}^{-1} \Theta\left(x-L_{v e g}\right) \Theta\left(h-Z_{c}\right)-1 m^{-1}|\partial h / \partial t|,
$$

where the Heaviside function $\Theta(s)$ (1 for $s>0 ; 0$ otherwise) defines the regions where plants can grow.

Parameters: We investigate model outcomes as function of the parameters characterizing the external forcing and the response of the system (the explored range is in parenthesis): the vertical vegetation limit $\mathrm{Z}_{\mathrm{c}}(0.02-$ $0.2 \mathrm{~m})$, frequency of HWEs $\mathrm{T}_{\mathrm{HWE}}(0-20 \mathrm{yr})$, mean total water elevation $\bar{R}(1-2 \mathrm{~m})$, rate S of RSLR $(0-0.02 \mathrm{~m} / \mathrm{yr})$ and the imposed onshore wind, characterized by the ratio of the undisturbed shear velocity $\mathrm{u}_{*_{0}}$ and the transport threshold $u_{t}(1.5-2.5)$, and by the fraction of the time $r_{t}$ the wind is above the transport threshold and sand is available.

\section{References}

1. Stutz, M. L. \& Pilkey, O. H. Open-Ocean Barrier Islands: Global Influence of Climatic, Oceanographic, and Depositional Settings. J. Coastal Res., 272, 207-222 (2011).

2. e.g. Emanuel, K. Downscaling CMIP5 climate models shows increased tropical cyclone activity over the $21 \mathrm{st}$ century. Proceedings of the National Academy of Sciences of the United States of America, 110(30), 12219-24 (2013).

3. e.g. IPCC, Climate Change 2014: Impacts, Adaptation and Vulnerability: Contributions of Working Group II to the Fifth Assessment Report of the Intergovernmental Panel on Climate Change, Cambridge Univ. Press, New York (2014).

4. Sallenger, A. H., Doran, K. S. \& Howd, P. a. Hotspot of accelerated sea-level rise on the Atlantic coast of North America. Nature Climate Change, 2(12), 884-888 (2012). 
5. McNamara, D. E. \& Keeler, A. A coupled physical and economic model of the response of coastal real estate to climate risk. Nature Climate Change, 3(3), 1-4 (2013).

6. Woodruff, J.D., Irish, J.L. \& Camargo, S.J. Coastal flooding by tropical cyclones and sea-level rise. Nature, 504(7478), 44-52 (2013).

7. e.g. FitzGerald, D.M, Fenster, M.S., Argow, B.A. \& Buynevich, I.V. Coastal impacts due to sea-level rise, Annu. Rev. Earth Planet. Sci., 36, 601-647 (2008).

8. Cazenave, A. \& Le Cozannet, G. Sea level rise and its coastal impacts. Earth's Future, 2, 1-20 (2013).

9. e.g. Blum, M. D. \& Roberts, H. H. Drowning of the Mississippi Delta due to insufficient sediment supply and global sea-level rise. Nature Geoscience, 2(7), 488-491 (2009).

10. e.g. Moore, L. J., List, J. H., Williams, S. J. \& Stolper, D. Complexities in barrier island response to sea level rise: Insights from numerical model experiments, North Carolina Outer Banks. J. Geophys. Res., 115 (F3) (2010).

11. Oster, D. The influence of morphology on barrier island recovery following storms: Insights from the Virginia Barrier Islands, Mid-Atlantic Bight, USA. Master's thesis, University of Virginia, Charlottesville, VA (2012).

12. Johnson, J. Geomorphic consequences of wave climate alteration along cuspate coastlines, Master's thesis, University of North Carolina, Chapel Hill, NC (2013).

13. Young, D., Porter, J., \& Bachmann, C. Cross-scale patterns in shrub thicket dynamics in the Virginia barrier complex. Ecosystems, (August), 854-863 (2007).

14. Durán, O. \& Moore, L. J. Vegetation controls on the maximum size of coastal dunes. Proc. Natl. Acad. Sci. USA, 110(43), 17217-22 (2013).

15. Barbour, M., Jong, T. \& Pavlik, B. Marine beach and dune plant communities. In B. Chabot \& H. Mooney (Eds.), Physiological Ecology of North American Plant Communities (pp. 296-322). Springer Netherlands (1985). 
16. Huiskes, A. Biological Flora of the British Isles: Ammophila Arenaria (L.) Link (Psamma Arenaria (L.) Roem. et Schult.; Calamgrostis Arenaria (L.) Roth). The Journal of Ecology, 67(1), 363-382 (1979).

17. Elbelrhiti, H., Claudin, P., \& Andreotti, B. Field evidence for surface-wave-induced instability of sand dunes. Nature, 437(7059), 720-3 (2005).

18. Sallenger, A. H. Storm impact scale for barrier islands. J. Coastal Res., 16(3), 890-895 (2000).

19. Byrne, M.-L. and McCann, S.B. The dunescape of sable island. The Canadian Geographer / Le Géographe canadien, 39, 363-368 (1995).

20. Fearnley, S. M., Miner, M. D., Kulp, M., Bohling, C. \& Penland, S. Hurricane impact and recovery shoreline change analysis of the Chandeleur Islands, Louisiana, USA: 1855 to 2005. Geo-Marine Letters, 29(6), 455-466 (2009).

21. Wolner, C. W. V., Moore, L. J., Young, D. R., Brantley, S. T., Bissett, S. N. \& McBride, R. A. Ecomorphodynamic feedbacks and barrier island response to disturbance: Insights from the Virginia Barrier Islands, Mid-Atlantic Bight, USA. Geomorphology, 199, 115-128 (2013).

22. e.g. Scheffer, M., S. Carpenter, J. A. Foley, C. Folke, and B. Walker, Catastrophic shifts in ecosystems, Nature, 413, 591-596, (2001).

23. e.g. McGlathery, K.J., Reidenbach, M.A., D’Odorico P.D., Fagherazzi, S., and Porter, J.H. Nonlinear Dynamics and Alternative Stable States in Shallow Coastal Systems, Oceanography 26(3), 220-231 (2013).

24. e.g. Fagherazzi, S., Carniello, S.L., D’Alpaos, L., \& Defina, A. Critical bifurcation of shallow microtidal landforms in tidal flats and salt marshes. Proc. Natl. Acad. Sci.USA 103(8), 337-8,341 (2006).

25. e.g. Marani, M., Da Lio, C. \& D’Alpaos, A. Vegetation engineers marsh morphology through multiple competing stable states. Proc. Natl. Acad. Sci.USA 110 (9), 3259-3263 (2013).

26. Walters, D., Moore, L.J., Durán, O., Fagherazzi, S. \& Mariotti, G. Interactions between barrier Islands and backbarrier marshes affect island system response to sea level rise: Insights from a coupled model. J. Geophys. Res._Earth Surf., 11, doi:10.1002/2014JF0033091 (2014). 
27. e.g. Scheffer, M., Bascompte, J., Brock, W. A., Brovkin, V., Carpenter, S. R., Dakos, V., Held, H., van Nes, E. H., Rietkerk, M. \& Sugihara, G. Early-warning signals for critical transitions. Nature, 451, 53-57 (2009).

28. Ruggiero, P., Komar, P. D., McDougal, W. G., Marra, J. J., Beach, R. A. Wave Runup, Extreme Water Levels and the Erosion of Properties Backing Beaches. J. Coastal Res., 17(2), 407-419 (2001).

29. Larson, M., Kubota, S. \& Erikson, K. Swash-zone sediment transport and foreshore evolution: Field experiments and mathematical modeling. Marine Geology, 212(14), 61-79 (2004).

30. Larson, M., Wise, R.A., \& Kraus, N.C. Coastal overwash, Part 2: Upgrade to SBEACH, ERDC/RSM- TN15, U.S. Army Engineer Research and Development Center, Vicksburg, MS. (2004).

\section{Acknowledgements}

Funding was provided by the Virginia Coast Reserve Long-Term Ecological Research Program (National Science Foundation DEB-123773), the Department of Energy's Office of Science through the Coastal Center of the National Institute for Climatic Change Research at Tulane University, the Geomorphology and Land use Dynamics Program of the National Science Foundation (EAR-1324973), and the University of North Carolina at Chapel Hill. The authors are grateful to A. Brad Murray (Duke University), Peter Haff (Duke University), and John Bruno (University of North Carolina-Chapel Hill) for helpful feedback on this manuscript prior to submission. The authors also thank two anonymous reviewers and editor Alistair Brown for helpful comments and suggestions that further improved this manuscript.

\section{Author information}

Correspondence and requests for materials should be addressed to oduran@marum.de.

\section{Author Contributions}

Both authors contributed extensively to this work.

\section{Competing Financial Interests}

The authors declare no competing financial interests. 
Figure 1. Empirical evidence for barrier island bistability. a-d, Examples of low (a,b) and high (c,d) barrier islands, i.e. islands without and with well-developed dunes, along the Virginia Barrier Islands, U.S. midAtlantic coast (included map): Paramore (a), Myrtle (b) and Hog (c, d). e, Alongshore island elevation (elevation of primary dune relative to beach berm) ${ }^{11}$ derived from 2005 lidar data (solid line) and average island elevation (solid circles). f, Probability density function (PDF) of measured elevations (symbols) with best fit by a bimodal Normal distribution (lines). The crossover elevation is used to define high (blue) and low (yellow) regions in (e). g, Average island shoreline change rate (squares), used as a proxy for island migration, and island width (triangles), as function of average island elevation $\mathrm{H}$. Shoreline change rates are calculated from shoreline positions in the period $1945-2005^{12}$ and island widths are calculated from reported data on island area ${ }^{13}$. h, PDF of simulated island elevations (circles) and simulated shoreline change rate (squares) rescaled by the value at the low state, as function of the average island elevation. Simulations were performed for $\gamma=1.5$. $\mathbf{i}-\mathbf{j}$, Photos illustrate shell armoring (i) and the exposure of marsh platform on the foreshore (j) at the two low elevation locations noted by corresponding symbols in the map.

Figure 2. Post-storm barrier island recovery. a, Post-storm evolution of island elevation (with and without vegetation) and vegetation cover fraction. $\mathrm{H}_{\mathrm{M}}$ is the maximum vegetated dune elevation, $\mathrm{T}_{\mathrm{v}}$ is the vegetation recovery time and $Z_{c}$ is the vegetation sensitivity to salt-water inundation. b-c, Simulated steady state for coastal dunes with (b) and without (c) vegetation. Dry-sand areas are yellow, vegetation is green and intertidal areas (i.e. below MHWL) are blue.

Figure 3. Bistability of island elevation. a-c, Evolution of the rescaled dune elevation $\mathrm{H} / \mathrm{H}_{\mathrm{M}}$ under a series of high water events (HWEs) with period $T_{H W E}=\gamma T_{v}$, for $\gamma=0.9$ (a), 2 (b) and 3 (c). $\gamma$ is the vulnerability index and $\mathrm{T}_{\mathrm{v}}$ is the vegetation recovery time. Symbols represent rescaled total water level $\mathrm{R} / \mathrm{H}_{\mathrm{M}}$. Red symbols denote extreme events (i.e. those leading to overwash). Elevations above $0.8 \mathrm{H}_{M}$ (high state) and below $0.2 \mathrm{H}_{\mathrm{M}}$ (low state) are highlighted in blue and yellow, respectively. d, Onset of bistability calculated from model runs for different parameters (triangles). Squares represent the particular cases shown in (a-c). Solid line: predicted bistability onset represented by the condition $\mathrm{T}_{\mathrm{HWE}}=\mathrm{T}_{\mathrm{v}}(\gamma=1)$. e, Equilibrium states for island elevation and probability of dune recovery (green symbols) as function of $\gamma$, for varying winds, rates of RSLR and vegetation sensitivities (see methods for range of parameter values used). Green line corresponds to the exponential fit $a^{\gamma-1}(\mathrm{a}=0.035)$ for the recovery probability (defined as the inverse of the average number of HWEs spent in the low state). Blue and orange lines are the average values for the stable high and low equilibrium respectively, and the shadow area on either side of the line represents the data dispersion. The onset of bistability, which 
occurs when the probability of dune recovery decreases below 1 (dashed line), and the processes leading to a transition between alternative states (arrows) are shown for reference. In the snapshots of simulated high and low islands, dry-sand areas are yellow, vegetation is green and intertidal areas (i.e. below MHWL) are blue.

Figure 4. Dynamical states and transitions. Barrier island response, in terms of the vulnerability index $\gamma$, as function of the net aeolian accretion rate $\left(\mathrm{G}_{0}-\mathrm{S}\right)$, where $G_{0}=\beta q_{0} \lambda^{-1}$, and the storm-vegetation parameter $T_{H W E} Z_{c}^{-1}$ (Eq. 1) in arbitrary units (a.u.). $\mathrm{S}$ is the rate of RSLR, $\mathrm{q}_{0}$ is the average aeolian sand flux, $\mathrm{Z}_{\mathrm{c}}$ is the minimum elevation above MHWL that vegetation can grow, $\lambda$ is the wavelength of the non-vegetated incipient dunes, $\mathrm{T}_{\mathrm{HWE}}$ is the period of HWE and $\beta$ is a fit parameter. The probability of dune, and therefore island, recovery (Fig. 3e) is shown in colors. Solid and dashed lines represent the onset of bistability and the transition to a potentially unstable barrier island (gray area), respectively. Circle: non-vegetated low islands with low aeolian sand transport (e.g. Alaska BIs ${ }^{1}$ ), Star: non-vegetated low islands having especially active aeolian sand transport (e.g. Baja California, Mexico), Diamond: stable high islands (e.g. the central two-thirds of 40-km-long Sable Island, Newfoundland ${ }^{19}$ ). Arrows represent suggested transitions taking place at the Chandeleurs Islands, Louisiana, U.S. (Triangles) and at the Virginia Barrier Islands, Virginia, U.S. (squares). Empty (solid) symbols represent suggested past (present) condition. The absence of vegetation is given by the limit $Z_{c} \rightarrow \infty$. 


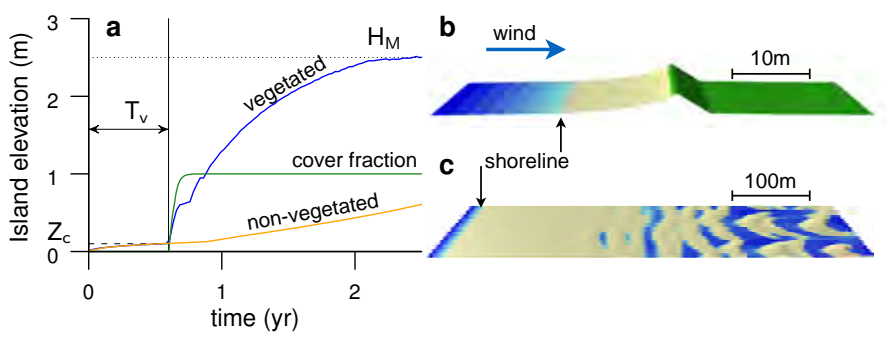




\section{Bistability of barrier islands induced by biophysical interactions} Orencio Durán Vinent and Laura J. Moore

\section{Supplementary Methods: Coastal Dune Model}

The coastal dune model describes the temporal evolution of the sand surface elevation $h(x, y, t)$-defined relative to the mean high water level (MHWL)-and the cover fraction $\rho_{\mathrm{veg}}(\mathrm{x}, \mathrm{y}, \mathrm{t})$ for a single generic grass species. $\mathrm{x}$ is the cross-shore distance to the shoreline $(\mathrm{x}=0)$, which separates the foreshore $(x<0)$ from the backshore $(x>0)$, and $\mathrm{y}$ is the alongshore coordinate.

Fluid dynamics. The model uses a linear solution of the Reynolds averaged Navier-Stokes equations for the turbulent boundary layer over smooth terrain to calculate the perturbation $\delta \tau$ of the undisturbed surface wind shear stress $\boldsymbol{\tau}_{0}$ induced by the topography h. The surface shear stress $\boldsymbol{\tau}$ is $\boldsymbol{\tau}(\mathrm{h})=\boldsymbol{\tau}_{0}+\tau_{0} \delta \boldsymbol{\tau}(\mathrm{h})$ (see Ref. 1 for details). For lee slopes steeper than the separation angle $\sim 20^{\circ}$, non-linear hydrodynamic effects are simply modeled by a separation streamline below which wind and flux are set to zero. Each streamline is defined by a third-order polynomial connecting the brink with the ground at the reattachment point ${ }^{2}$.

Shear stress partition. In the presence of vegetation, plants act as roughness elements that absorb part of the momentum transferred to the sand surface by the wind, effectively reducing the surface shear stress and thus the sand transport rate. For randomly distributed plants, and assuming the effective shelter area for one plant is proportional to its basal area, the fraction $\tau_{\mathbf{s}}$ of the surface shear stress acting on the sand decreases with the local vegetation cover fraction $\rho_{\text {veg }}$ as

$$
\tau_{\mathrm{s}}=\tau /\left(1+\Gamma \rho_{\mathrm{veg}}\right)
$$


where $\Gamma$ is a dimensionless 'roughness factor' that describes the effectiveness of the vegetation in slowing down the flow and thus in trapping sand. In the model, $\Gamma=16$ is calculated from values of plant form drag and geometry reported for creosote communities (see Ref. 1 and references therein; it is reasonable to expect a similar value for coastal grasses and desert bushes due to a roughly similar plant geometry).

Effect of wetting on the transport threshold. We further consider that at the shore, transport is naturally limited by the elevation $\mathrm{h}$ relative to the watertable, as the transport threshold $\tau_{\mathrm{t}}$ is much higher for wet grains than for dry ones. This relation is captured by the simple phenomenological expression

$$
\tau_{\mathrm{t}}(\mathrm{h})=\tau_{\mathrm{t}}^{\mathrm{d}}+\left(\tau_{\mathrm{t}}^{\mathrm{w}}-\tau_{\mathrm{t}}^{\mathrm{d}}\right) \exp \left(-\left(\mathrm{h}+\mathrm{H}_{\text {water }}\right) / \delta_{\mathrm{w}}\right)
$$

where $\tau_{\mathrm{t}}^{\mathrm{d}}$ and $\tau_{\mathrm{t}}^{\mathrm{w}}=10 \tau_{\mathrm{t}}^{\mathrm{d}}$ are the thresholds for dry and wet sand respectively, $\mathrm{H}_{\text {water }}$ is the watertable depth relative to the MHWL and $\delta_{\mathrm{w}}=0.05 \mathrm{~m}$ characterizes the decrease in water content of the sand as a function of elevation. At the watertable $\left(\mathrm{h}=-\mathrm{H}_{\text {water }}\right.$, relative to the $\mathrm{MHWL}$ ) we get by definition $\tau_{\mathrm{t}}=\tau_{\mathrm{t}}^{\mathrm{w}}$, whereas far above it $\tau_{\mathrm{t}} \rightarrow \tau_{\mathrm{t}}^{\mathrm{d}}$.

Aeolian sand transport. The sand flux is determined from the shear stress at the sand surface $\tau_{\mathbf{s}}$ (Eq.1), the surface gradient $\nabla \mathrm{h}$ and the transport threshold $\tau_{\mathrm{t}}$ (Eq.2). It is well known that the sand flux $\mathbf{q}_{\mathrm{a}}$ over an erodible surface increases with the distance downwind as the saltation process spatially adjusts to the wind forcing. This effect is modeled as

$$
\nabla \cdot \mathbf{q}_{\mathrm{a}}=\left(\mathrm{q}_{\mathrm{a}}+\delta_{\mathrm{a}}\right)\left(1-\mathrm{q}_{\mathrm{a}} / \mathrm{q}_{\mathrm{sat}}\right) / \mathrm{l}_{\mathrm{sat}}
$$

which describes the spatial relaxation of the sand flux toward an equilibrium 'saturated' value $\mathrm{q}_{\text {sat }}$ over a 'saturation' length $I_{\text {sat }}$. The saturated flux and saturation length are defined as: $\mathbf{q}_{\mathrm{sat}}=\mathrm{Q}\left(\tau_{\mathrm{s}}-\tau_{\mathrm{t}}\right) / \tau_{\mathrm{t}}^{\mathrm{d}}$ and $\mathrm{I}_{\text {sat }}=\mathrm{L} \tau_{\mathrm{t}}^{\mathrm{d}} /\left(\tau_{\mathrm{s}}-\tau_{\mathrm{t}}\right)$, where $\mathrm{Q}(\nabla \mathrm{h})$ and $\mathrm{L}(\nabla \mathrm{h})$ are slope-dependent dimensional functions ${ }^{2}$. The small term $\delta_{\mathrm{a}} \sim 10^{-2} \mathrm{q}_{\mathrm{sat}}$ quantifies the direct sand entrainment in the absence of transport when the bed shear stress has just crossed the transport threshold. For simplicity in the formulation $q_{a}$ is defined as a volume, not mass, flux. 
Storms. Storms are defined in the model as high water events (HWEs) with total water elevation R above the MHWL ( $R$ is defined relative to the MHWL). HWEs are considered periodic with period $T_{H W E}$ and have a constant duration $\Delta T$. $R$ is randomly distributed according to an Erlang distribution $R^{2} \bar{R}^{-3} e^{-3 R / \bar{R}}(\bar{R}$ is mean total water elevation) which has an exponential tail, in agreement with Ref. 3, and filters tidal events (i.e. there are no events for $\mathrm{R} \rightarrow 0$ ).

Storm-induced sand transport. We derive a simple phenomenological expression to calculate the crossshore net sand flux $\mathrm{q}_{\mathrm{st}}(\mathrm{x}, \mathrm{y}, \mathrm{t})$ for elevations between MHWL and R during high water events (HWE). Based on Ref. 4 (see Ref. 5 for the validation of a similar formulation), we assume the net sand flux $q_{s t}$ over many swash cycles to be proportional to the cube of the average speed $U$ of the uprushing wave front, times the time $\delta \mathrm{t}$ this particular location is submerged: $\mathrm{q}_{\mathrm{st}} \propto \mathrm{U}^{3} \delta \mathrm{t} /(\mathrm{gT})$, with gravity g and timescale $\mathrm{T}$. The sand flux is further weighted by a downslope contribution $\left(1-\partial_{x} \mathrm{~h} / \tan (\alpha)\right)$ that represents the tendency of the surface to reach the equilibrium foreshore slope $\tan (\alpha)$. From energy conservation (neglecting the dissipation due to bottom friction), the kinetic energy of the uprushing wave front is balanced by its potential energy. In that case $U \propto \sqrt{\mathrm{g}(\mathrm{R}-\mathrm{h})}$ and $\delta \mathrm{t} \propto \sqrt{(\mathrm{R}-\mathrm{h}) / \mathrm{g}}$ (Ref. 4), which lead to:

$$
\mathrm{q}_{\mathrm{st}}=\mathrm{T}^{-1}(\mathrm{R}-\mathrm{h})^{2}\left(1-\partial_{\mathrm{x}} \mathrm{h} / \tan (\alpha)\right) .
$$

The timescale $\mathrm{T}$ is arbitrary (although much smaller than the timescale of aeolian transport) and we choose the rescaled duration of HWEs $(\Delta T / T=100)$ to qualitatively reproduce the main erosional regimes described in Ref. 6 (Supplementary Fig. 5).

Surface dynamics. Foreshore $(\mathrm{x}<0)$ : We assume the foreshore to be always at equilibrium $(\partial \mathrm{h} / \partial \mathrm{t}=0)$ with a constant shape defined by the initial condition. This assumption implies aeolian erosion is balanced by accretion in the swash zone. As a result, the simulated foreshore acts as a sand reservoir supplying an unlimited amount of sediment to the backshore, effectively feeding dune formation and post-storm recovery. Shoreline $(\mathrm{x}=0)$ : We assume, as a first approximation, that under relative sea level rise (RSLR) the shoreline follows Bruun's rule ${ }^{7}$ and migrates landward at a rate $\dot{x}_{\text {shore }}=50 \mathrm{~S}$, proportional to the rate $\mathrm{S}$ of RSLR with a prefactor within the typical range ${ }^{8}$. Backshore $(x>0)$ : Following the timescale separation 
between RSLR, aeolian and storm-induced transport, we calculate the change of the sand surface elevation $\mathrm{h}$ at the backshore from mass conservation as

$$
\frac{\partial \mathrm{h}}{\partial \mathrm{t}}=-\frac{\partial \mathbf{q}_{\mathrm{st}}}{\partial \mathrm{x}}
$$

during HWEs, and as

$$
\frac{\partial \mathrm{h}}{\partial \mathrm{t}}=-\nabla \cdot \mathbf{q}_{\mathrm{a}}-\mathrm{S}+\dot{\mathrm{x}}_{\text {shore }} \frac{\partial \mathrm{h}}{\partial \mathrm{x}}
$$

otherwise. The last two terms in the right hand side of Eq. 6 describe the effects of relative sea level rise. Because we define the surface elevation relative to the sea level and the shoreline position, the surface effectively sinks under RSLR (term -S) while it apparently moves towards the shoreline (last term). Avalanches: For slopes steeper than the angle of repose $34^{\circ}$, an additional dissipative flux models the surface relaxation due to avalanches ${ }^{2}$.

Vegetation dynamics. As a first approximation, we assume a single generic grass species with a cover fraction $\rho_{\text {veg }}$ that is sensitive to sand erosion and accretion and that can increase up to the maximum cover $\rho_{\text {veg }}=1$ during a characteristic time $t_{\text {veg }}$. We further assume plant growth is also sensitive to frequent saltwater inundation and thus to the proximity of the shoreline and to the elevation above MHWL. Therefore, plants can effectively grow only landward of the vegetation limit $L_{\text {veg }}$ and in places higher than a minimum elevation $Z_{c}$ from MHWL. Thus,

$$
\frac{\mathrm{d} \rho_{\mathrm{veg}}}{\mathrm{dt}}=\frac{1-\rho_{\mathrm{veg}}}{\mathrm{t}_{\mathrm{veg}}} \Theta\left(\mathrm{x}-\mathrm{L}_{\mathrm{veg}}\right) \Theta\left(\mathrm{h}-\mathrm{Z}_{\mathrm{c}}\right)-\frac{\gamma}{\mathrm{H}_{\mathrm{veg}}}\left|\frac{\partial \mathrm{h}}{\partial \mathrm{t}}\right|
$$

where $\gamma$ is plant sensitivity to sand erosion/accretion, $\mathrm{H}_{\mathrm{veg}}$ is the maximum plant height and the Heaviside function $\Theta(s)$ (1 for $s>0$; 0 otherwise) defines the regions where plants can grow. Both the growth time $\mathrm{t}_{\mathrm{veg}}$ and the sensitivity $\gamma$ are in general a function of the erosion/accretion rate $\partial \mathrm{h} / \partial \mathrm{t}$, which can be varied for different plant species. However, we find that the results presented here are independent of these considerations. Therefore, for simplicity and in agreement with Ref. 1, we use a constant growth time $t_{\text {veg }}=3$ days, and sensitivity $\gamma=1$, with $H_{\text {veg }}=1 \mathrm{~m}$. We further assume vegetation dies in all places submerged during high water events. 
Initial Condition. Sand surface (Eqs. $5 \&$ 6): The sand surface elevation $\mathrm{h}$ is initially defined as an inclined plane $h(x, y)=\tan (\alpha) x$ at the foreshore $(x<0)$, and as a flat surface $h(x, y)=0$ at the backshore $(x>0)$, where $\alpha$ is the beach slope. In the simulations $\alpha=1^{\circ}$. Vegetation (Eq. 7): We assume no initial vegetation $\left(\rho_{\mathrm{veg}}=0\right)$.

Boundary conditions. Aeolian transport (Eq. 3): We assume no aeolian sand influx $\left(\mathrm{q}_{\mathrm{a}}=0\right)$ at the most seaward limit of the foreshore, where the surface elevation equals the mean low water level (MLWL) and thus the sand is effectively wet at all times and not available for aeolian transport. Storm-induced transport (Eqs. 4 \& 5): We impose a Dirichlet boundary condition. During overwashes $(\mathrm{R}>\mathrm{H})$ the boundary condition is $\mathrm{h}=0$ at both the upstream boundary (the shoreline) and the downstream one, at the landward limit of the simulation domain. During the erosional regime $(\mathrm{R}<\mathrm{H})$, the seaward condition is the same but the landward one becomes $\mathrm{q}_{\mathrm{st}}=0$ at the line $\mathrm{y}(\mathrm{x})$ where $\mathrm{h}(\mathrm{x}, \mathrm{y}, \mathrm{t})=\mathrm{R}$ seaward of the dune.

Integration. We integrate the model within a two-dimensional domain large enough to include the resulting morphology. The grid spacing and time step are typically $\sim 1 / 4 \mathrm{~m}$ and $\sim 1 / 2$ hour, respectively, and are selected to resolve the smallest length and temporal scales involved in the problem, the saturation length $I_{\text {sat }}$ and time $\mathrm{l}_{\mathrm{sat}}^{2} / \mathrm{q}_{\mathrm{sat}}$. For simplicity all boundary conditions are uniform in the alongshore direction $\mathrm{y}$.

Parameters. We investigate model outcomes as function of the parameters characterizing the external forcing and the response of the system (the explored range is in parenthesis): the vertical vegetation limit $Z_{c}$ (0.02-0.2m), frequency of HWEs $T_{H W E}(0-20 \mathrm{yr})$, mean total water elevation $\bar{R}(1-2 \mathrm{~m})$, rate $\mathrm{S}$ of RSLR $(0-$ $0.02 \mathrm{~m} / \mathrm{yr}$ ) and the imposed onshore wind, characterized by the ratio of the undisturbed shear velocity $\mathrm{u}_{* 0}$ and the transport threshold $u_{t}(1.5-2.5)$, which is assumed constant and oriented along the cross-shore direction throughout each simulation. Notice that by definition $\mathrm{u}_{* 0} / \mathrm{u}_{\mathrm{t}}=\sqrt{\tau_{0} / \tau_{\mathrm{t}}}$ where $\tau_{0}$ is the undisturbed bed shear stress and $\tau_{\mathrm{t}}$ is the threshold. Simulation time is thus shorter than in more realistic wind conditions, where the wind intensity fluctuates daily and seasonally, beach sand could be wet (i.e. transport threshold becomes very large) or sand supply is limited. The conversion factor is loosely defined by the fraction of the time $r_{t}$ the wind is above the transport threshold and sand is available. Although the value $r_{t}=0.02$ is typically used it is important to note that this parameter essentially rescales time for all processes involved. 


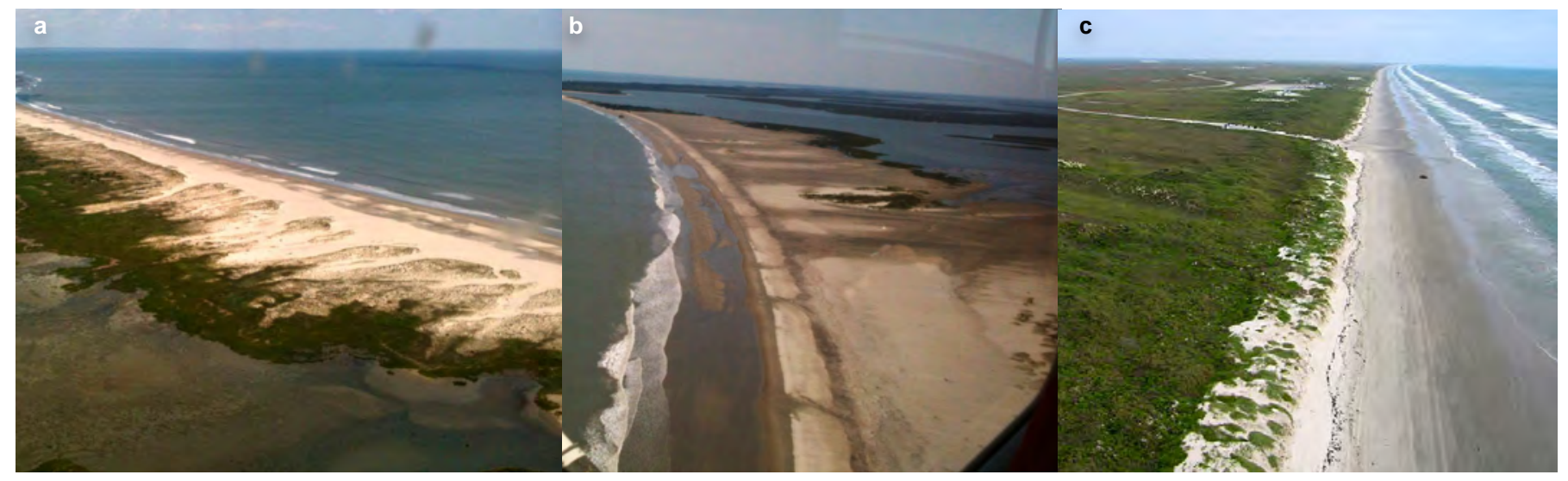

Supplementary Figure 1. Examples of low $(\mathrm{a}, \mathrm{b})$ and high (c) barrier islands. Virginia Barrier Islands: Metompkin (a) and Paramore (b). (c) Padre Island, Texas.

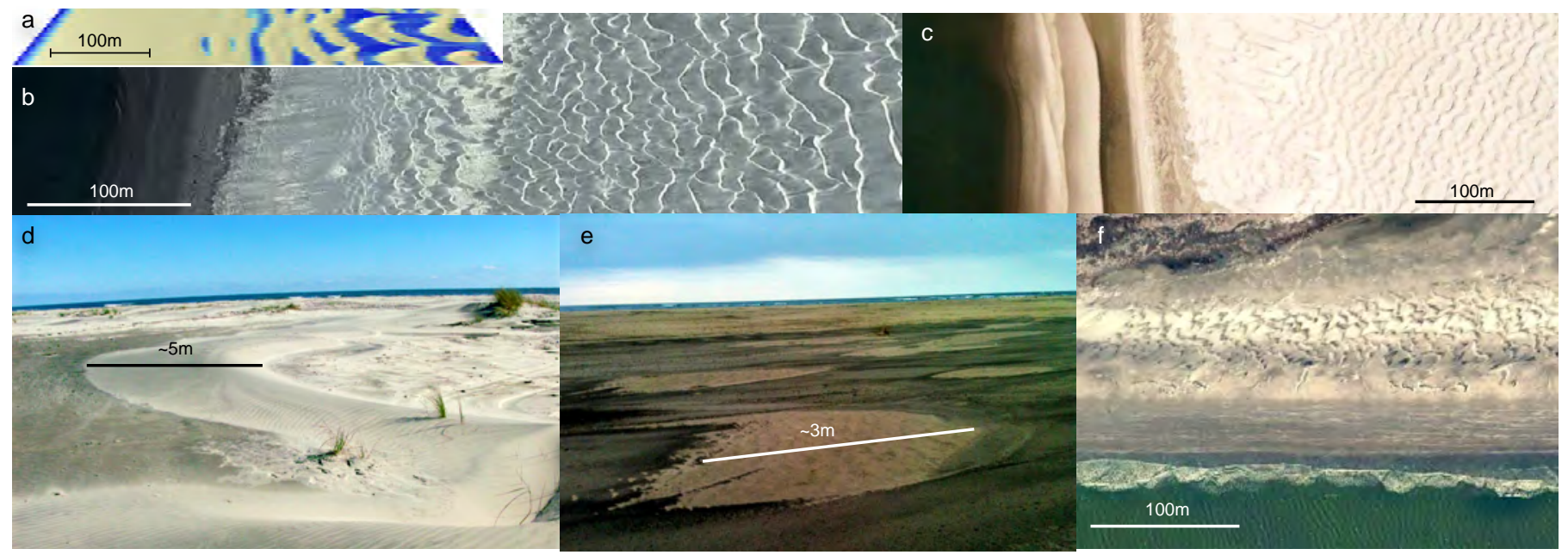

Supplementary Figure 2. Examples of nucleation of non-vegetated dunes at the back of the beach of barrier islands in Baja California, Mexico (b), Pellworm, Germany (c), and Virginia, U.S. (Hog Island (d), Metompkin Island (e) and Wreck Island (f)). The equivalent numerical simulation is shown for comparison (a). 

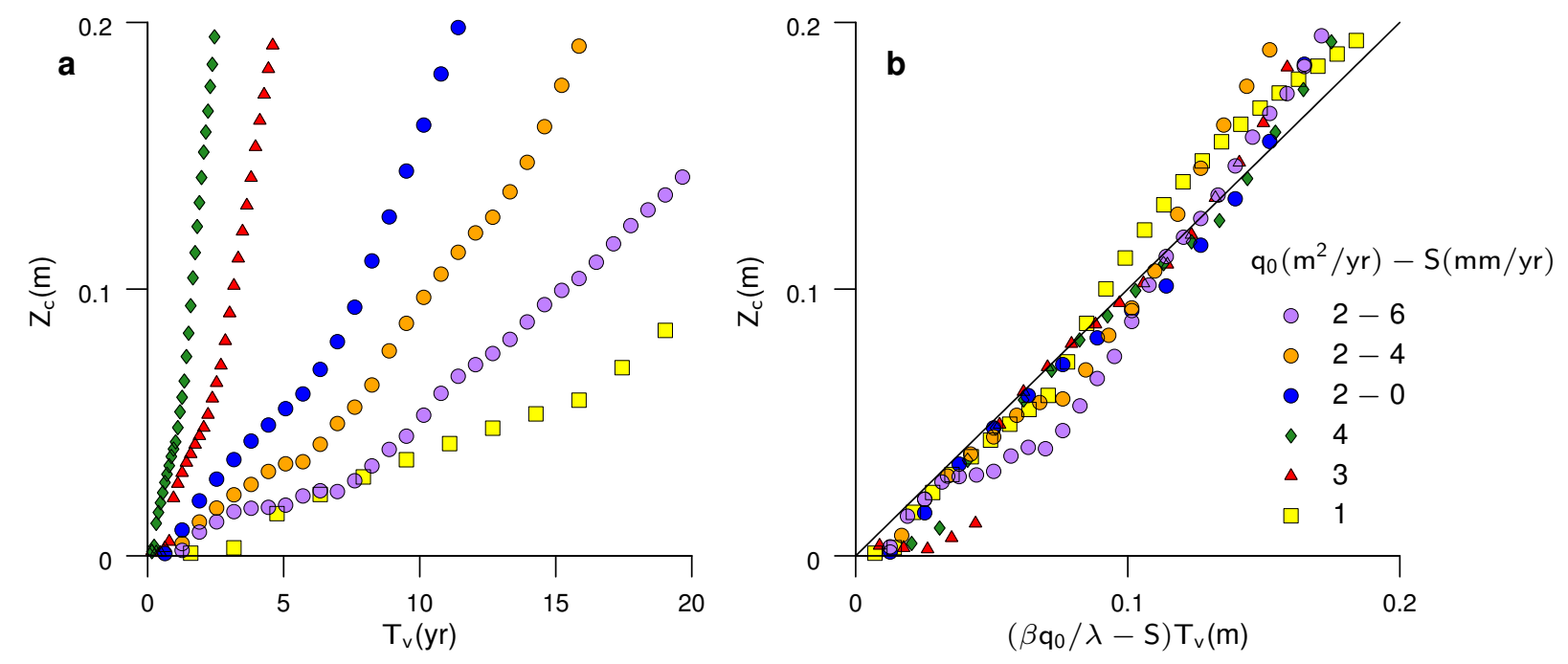

Supplementary Figure 3. (a) Vegetation recovery time $\left(T_{v}\right)$ needed for a given vegetation sensitivity $\left(Z_{c}\right)$, imposed average aeolian flux $\left(\mathrm{q}_{0}\right)$ and relative sea level rise rate $\mathrm{S}$. (b) Collapse after time is rescaled by the net sand accretion rate $\beta \mathrm{q}_{0} \lambda^{-1}-\mathrm{S}$, where $\beta=0.08$ is a fitting parameter and $\lambda \approx 10 \mathrm{~m}$ is the wavelength of the non-vegetated incipient dunes, a function of the imposed wind shear velocity $\left(\mathrm{u}_{*}\right)$. Solid line represents the relation given in the main text. 


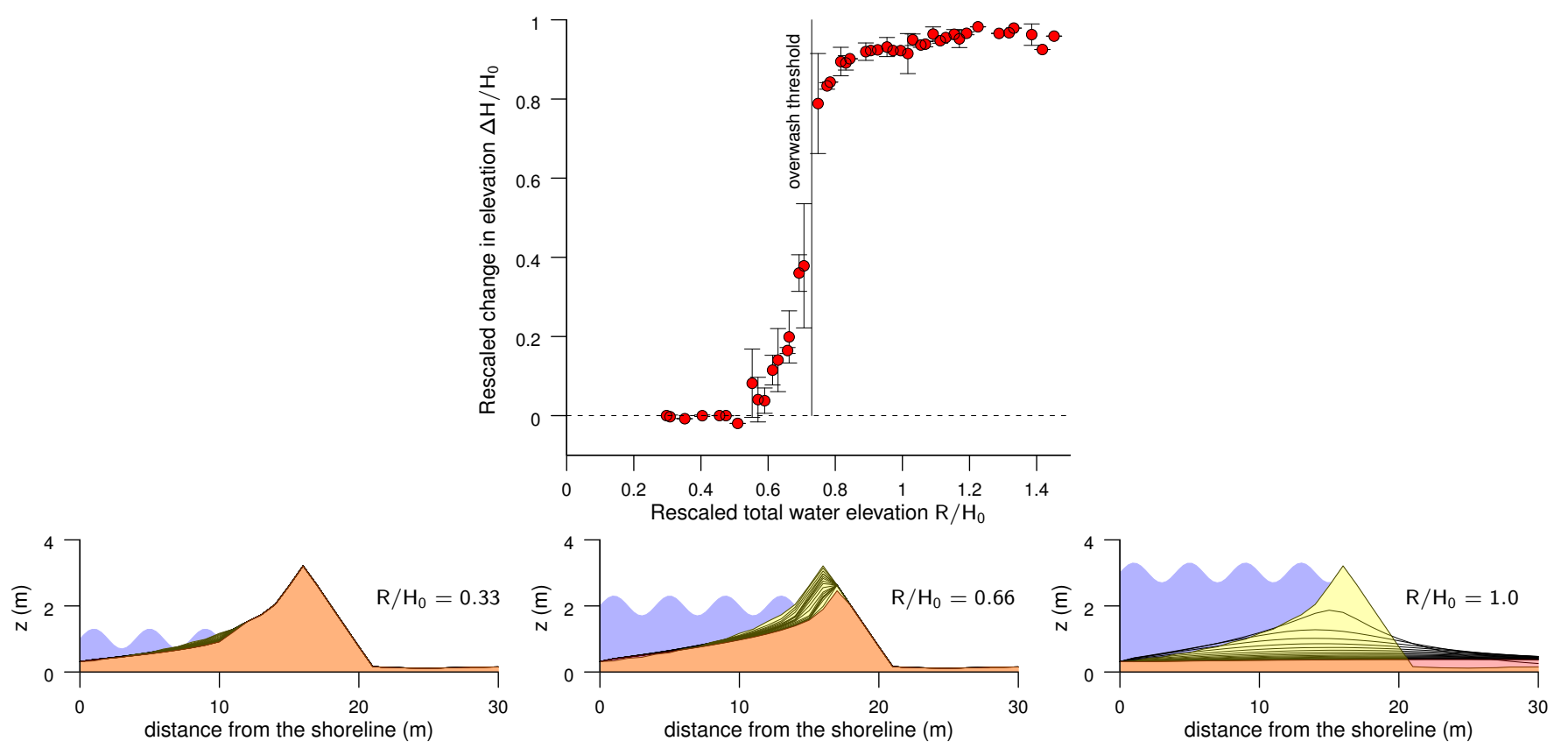

Supplementary Figure 4. Top: change in dune elevation $(\Delta H)$ for a dune of height $H_{0}$ after a high water event of total water elevation R. Bottom: model outcomes for different values of $R / H_{0}$ illustrating the main responses to storm impact, according to Ref. 6: swash regime (left), collisional regime (center) and overwash regime (right). Initial and final elevations are shown in yellow and orange, respectively, with intermediate states in solid lines. The blue area illustrates total water elevation during a HWE. 

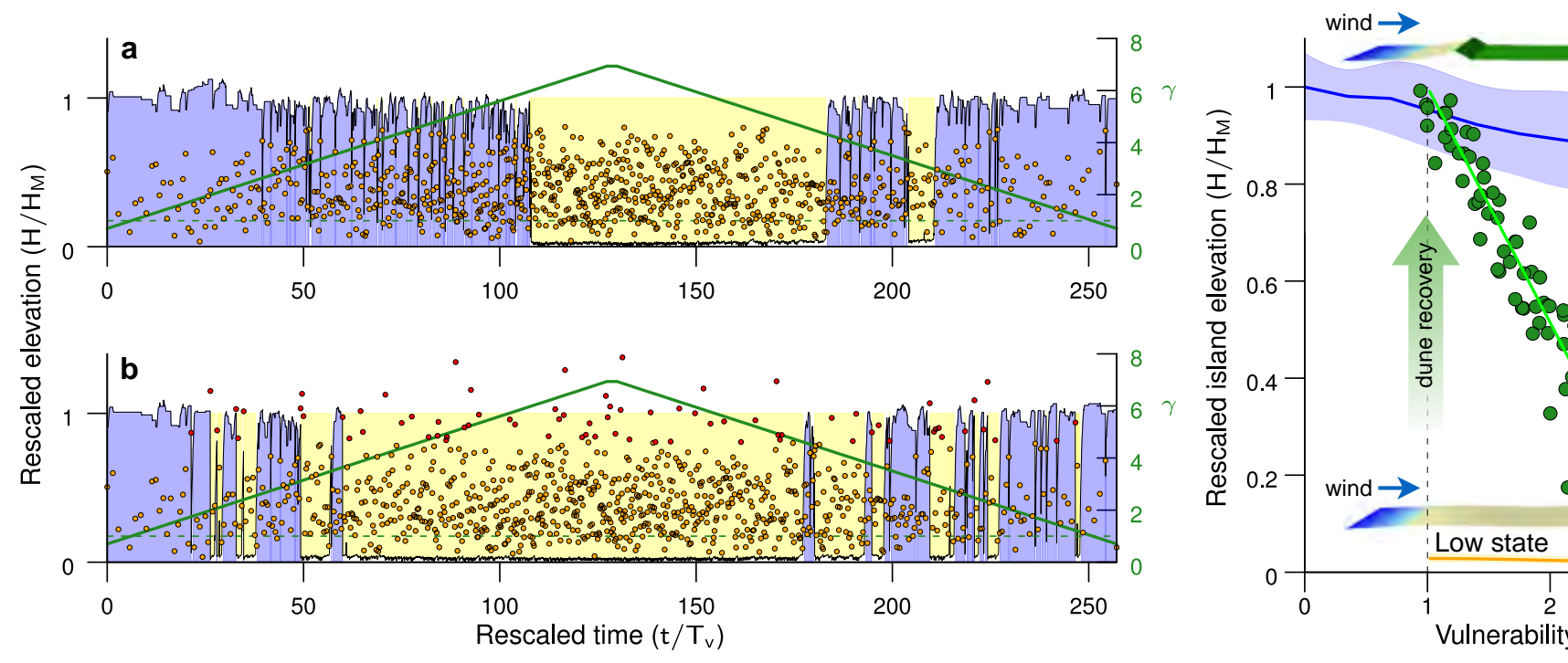

Supplementary Figure 5. Simulated island response to gradually changing conditions, represented by an increasing and then decreasing vulnerability index ( $\gamma$, green solid line). The evolution of the rescaled dune elevation after a series of HWEs is shown both excluding (a) and including (b) extreme high water events (defined as those events leading to overwash). Notice the hysteresis in the absence of extreme events (a) as dune recovery (transition from a low-elevation to a high-elevation state) effectively takes place at a lower vulnerability index $\gamma$ than the one needed for severe dune erosion (transition from a high-elevation to a lowelevation state). Dashed green line represents the onset of bistability $(\gamma=1)$. Simulations were conducted for typical parameters and without RSLR. Symbols represent rescaled total water elevation $R / H_{M}$. Extreme events are indicated by red symbols. Elevation is rescaled by the maximum dune height $\mathrm{H}_{M}$ and time is rescaled by the vegetation recovery time $T_{v}$. Elevations above $0.8 \mathrm{H}_{M}$ (high state) and below $0.2 \mathrm{H}_{M}$ (low state) are highlighted in blue and yellow, respectively. 


\section{Supplementary References}

1. Durán, O., Silva, M.V.N., Bezerra, L.J.C., Herrmann, H.J. \& Maia, L.P. Measurements and numerical simulations of the degree of activity and vegetation cover on parabolic dunes in north-eastern Brazil. Geomorphology 102, 460-471. (2008).

2. Durán, O., Parteli, E.J.R. \& Herrmann, H.J. A continuous model for sand dunes: Review, new developments and application to barchan dunes and barchan dune fields. Earth Surf. Proc. Land. 35, 1591-1600. (2010).

3. Ruggiero, P., Komar, P. D., Mcdougal, W. G., Marra, J. J., Beach, A. R. Wave Runup, Extreme Water Levels and the Erosion of Properties Backing Beaches. J. Coastal Res., 17(2), 407-419 (2001).

4. Larson, M., Kubota, S. \& Erikson, K. Swash-zone sediment transport and foreshore evolution: Field experiments and mathematical modeling. Marine Geology, 212(14), 61-79 (2004).

5. Larson, M., Wise, R.A., \& Kraus, N.C. Coastal overwash, Part 2: Upgrade to SBEACH, ERDC/RSMTN-15, U.S. Army Engineer Research and Development Center, Vicksburg, MS. (2004).

6. Sallenger, A. H. Storm impact scale for barrier islands. J. Coastal Res., 16(3), 890895 (2000).

7. Bruun, P. Sea-level rise as a cause of shore erosion. J. Waterways Harbors Div. 88, 117-130 (1962).

8. e.g. FitzGerald, D.M, Fenster, M.S., Argow, B.A. \& Buynevich, I.V. Coastal impacts due to sea-level rise, Annu. Rev. Earth Planet. Sci., 36, 601-647 (2008). 